Check for updates

Cite this: J. Mater. Chem. A, 2018, 6, 9604

Received 13th March 2018 Accepted 23rd April 2018

DOI: $10.1039 / c 8 t a 03501 f$

rsc.li/materials-a

\section{Photodecomposition and thermal decomposition in methylammonium halide lead perovskites and inferred design principles to increase photovoltaic device stability $\dagger$}

\author{
Emilio J. Juarez-Perez, (D) Luis K. Ono, (D) Maki Maeda, Yan Jiang, (D) Zafer Hawash (D) \\ and Yabing Qi $\mathbb{D}$ *
}

Hybrid lead halide perovskites have emerged as promising active materials for photovoltaic cells. Although superb efficiencies have been achieved, it is widely recognized that long-term stability is a key challenge intimately determining the future development of perovskite-based photovoltaic technology. Herein, we present reversible and irreversible photodecomposition reactions of methylammonium lead iodide $\left(\mathrm{MAPb}_{3}\right)$. Simulated sunlight irradiation and temperature $\left(40-80^{\circ} \mathrm{C}\right)$ corresponding to solar cell working conditions lead to three degradation pathways: (1) $\mathrm{CH}_{3} \mathrm{NH}_{2}+\mathrm{HI}$ (identified as the reversible path), (2) $\mathrm{NH}_{3}+\mathrm{CH}_{3}$ l (the irreversible or detrimental path), and (3) a reversible $\mathrm{Pb}(0)+\mathrm{I}_{2}(\mathrm{~g})$ photodecomposition reaction. If only the reversible reactions (1) and (3) take place and reaction (2) can be avoided, encapsulated $\mathrm{MAPb}_{3}$ can be regenerated during the off-illumination timeframe. Therefore, to further improve operational stability in hybrid perovskite solar cells, detailed understanding of how to mitigate photodegradation and thermal degradation processes is necessary. First, encapsulation of the device is necessary not only to avoid contact of the perovskite with ambient air, but also to prevent leakage of volatile products released from the perovskite. Second, careful selection of the organic cations in the compositional formula of the perovskite is necessary to avoid irreversible reactions. Third, selective contacts must be as chemically inert as possible toward the volatile released products. Finally, hybrid halide perovskite materials are speculated to undergo a dynamic formation and decomposition process; this can gradually decrease the crystalline grain size of the perovskite with time; therefore, efforts to deposit highly crystalline perovskites with large crystal sizes may fail to increase the long-term stability of photovoltaic devices.

\section{Introduction}

Hybrid lead halide perovskites have been intensively evaluated as light harvesting materials for photovoltaic cells since 2009. ${ }^{1}$ Currently, the long-term stability of perovskite solar cells is a major challenge that will require substantial effort to advance hybrid perovskite solar cells towards commercialization. ${ }^{2}$ Moreover, a significant number of research groups are achieving power conversion efficiencies of over $20 \%$ using hybrid perovskite devices; ${ }^{3}$ however, very few devices have succeeded in operational stability tests or shown lifetimes longer than 1000 hours at the maximum power point. ${ }^{3}$ However, promising attempts have been realized recently to improve the durability of these cells using different approaches such as

Energy Materials and Surface Sciences Unit (EMSSU), Okinawa Institute of Science and Technology Graduate University (OIST), 1919-1 Tancha, Onna-son, Okinawa 904-0495, Japan. E-mail: Yabing.Qi@OIST.jp

$\dagger$ Electronic supplementary information (ESI) available. See DOI: $10.1039 / \mathrm{c} 8 \mathrm{ta0} 03501 \mathrm{f}$ chemically inert scaffolds and electrodes ${ }^{4}$ or mixed/multication hybrid perovskites. ${ }^{5}$ How hybrid perovskite suffers from degradation and what products are generated during the degradation are important questions to be answered in order to design stable perovskite-based solar cells. Furthermore, understanding reversible degradation routes or so-called selfhealing in perovskite solar cells, in which the cell performance recovers its original value after resting in the dark, has recently received attention as a strategy to prolong device lifetimes. ${ }^{6}$ In the decomposition pathways of methylammoniumbased perovskites, the degradation processes that must be avoided are irreversible degradation reactions that permanently limit the lifetimes of solar cells. Therefore, understanding the fundamental processes taking place in both reversible and irreversible degradation pathways is a step forward to enhance the stability of solar cells. Our group recently found that $\mathrm{MAPbI}_{3}$ perovskite degrades significantly faster upon exposure to $\mathrm{I}_{2}$ vapor than to $\mathrm{H}_{2} \mathrm{O}, \mathrm{O}_{2}$, or light only. ${ }^{7}$ As highlighted by Wilks and Bär, ${ }^{8}$ we proposed that the internally generated $I_{2}$ and its 
migration within $\mathrm{MAPbI}_{3}$ induced by solar cell operation and/or external stimuli (such as $\mathrm{H}_{2} \mathrm{O}, \mathrm{O}_{2}$, light irradiation, applied bias, and heat) leads to self-sustaining and irreversible degradation reactions in perovskites independent of the device architecture. ${ }^{7}$ Additionally, we recently showed that $\mathrm{CH}_{3} \mathrm{I}$ and $\mathrm{NH}_{3}$ are generated as irreversible gas by-products during high temperature thermal degradation of $\mathrm{MAPbI}_{3} .{ }^{9}$ However, the conditions under which detrimental $\mathrm{I}_{2}$ is generated remain unclear.

Interestingly, this puzzle is associated with a study published by Dawood et al. half a century ago regarding lead iodide $\left(\mathrm{PbI}_{2}\right){ }^{10} \mathrm{PbI}_{2}$ is a relevant material to the topic of perovskite solar cells. For example, $\mathrm{PbI}_{2}$ is a standard reagent choice to synthesize hybrid perovskite; also, it is the unique remaining solid degradation product after degradation of $\mathrm{MAPbI}_{3}$. Dawood et al. found that $\mathrm{PbI}_{2}$ suffers photodecomposition to iodine gas $\left(\mathrm{I}_{2}\right)$ and lead $\left(\mathrm{Pb}^{0}\right)$ upon interaction with visible light by observing the decrease in electrical conductivity under illumination wavelengths above the $\mathrm{PbI}_{2}$ band gap. ${ }^{10}$ Thus, they suggested the following stepwise $\mathrm{PbI}_{2}$ photodecomposition route: (I) photodecomposition of $\mathrm{PbI}_{2}$ takes place, assisted by a mechanism in which two excitons are generated (two electron-hole pairs); (II) these two excitons react, leading to the

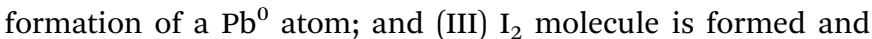
released, leaving two positively charged anion vacancy sites $\left(\mathrm{V}_{\mathrm{I}}^{*}\right)^{\mathbf{1 1}}$ (see Fig. 1a).

By reexamining Dawood et al.'s work, here, we present the following two points: (1) systematical investigation of the lightonly decomposition pathways of $\mathrm{PbI}_{2}$ by verifying that our experimental setup (Fig. 1b) can detect $\mathrm{I}_{2}$ release and then pursuing detection of gas release from $\mathrm{MAPbI}_{3}$; and (2) photodecomposition experiments on $\mathrm{MAPbBr}_{3}$, aiming to answer the question of why $\mathrm{MAPbBr}_{3}$ is more stable than $\mathrm{MAPbI}_{3}$ perovskite.

Our experiments were performed in a home-built small vacuum chamber in the absence of $\mathrm{H}_{2} \mathrm{O}$ and $\mathrm{O}_{2}$, eliminating all other possible external degradation factors. Inside this vacuum chamber, applied light and/or heat and measured temperatures were accomplished in situ directly on the sample holder, and the gaseous species released during photodecomposition were probed using a quadrupole mass spectrometer (MS) equipped with an electron multiplier detector. Based on this setup, the light-induced activation energies for $\mathrm{I}_{2}$ release from $\mathrm{PbI}_{2}$ and $\mathrm{MAPbI}_{3}$ were extracted and compared. Thin films of $\mathrm{PbI}_{2}$, $\mathrm{MAPbI}_{3}$ and $\mathrm{MAPbBr}_{3}$ materials before and after the photodecomposition procedure were studied by X-ray photoelectron spectroscopy (XPS) and X-ray diffraction (XRD) to identify the remaining non-volatile degraded solid products. Finally, we also investigated whether photodegraded $\mathrm{PbI}_{2}$ films containing $\mathrm{Pb}^{0}$ could be recovered to $\mathrm{PbI}_{2}$ by exposure to $\mathrm{I}_{2}$ pellets at room temperature, which showed the reversibility of this photodecomposition. We propose that the decomposition of hybrid lead halide perovskite materials under mild visible illumination and temperature conditions is reversible; i.e., a continuously decomposing and re-forming dynamical process takes place which establishes a chemical equilibrium between the gas phase components and solid perovskite (Fig. 1e).

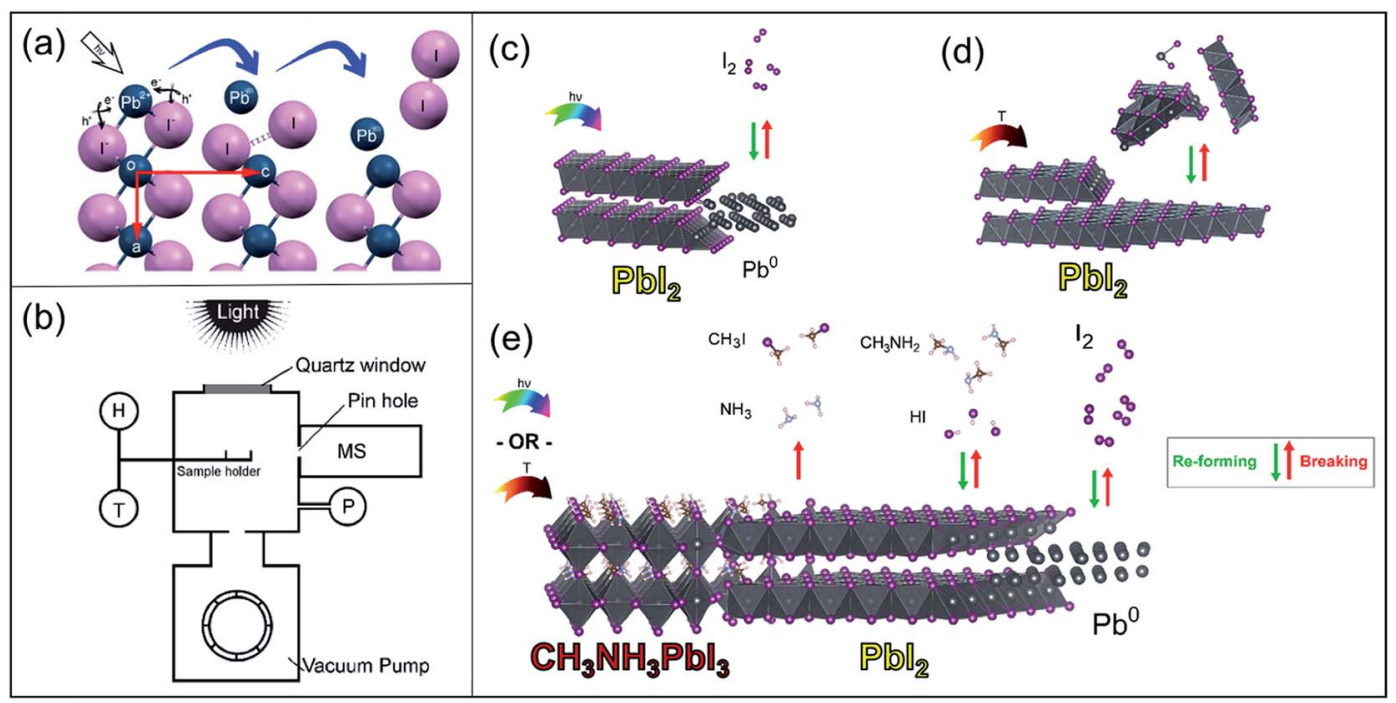

Fig. 1 Schematics of the photodecomposition, thermal evaporation and thermal degradation processes in $\mathrm{Pbl}_{2}$ and $\mathrm{MAPbl}_{3}$. (a) $(0 \mathrm{k} 0)$ plane view of a layered $\mathrm{Pbl}_{2}$ supercell. The figure depicts the two steps for the release of $\mathrm{I}_{2}$ and generation of $\mathrm{Pb}^{0}$ by the two-exciton mechanism. (b) Schematic of the experimental setup for controlled $\mathrm{Pbl}_{2}$ and perovskite degradation experiments. $\mathrm{H}$ : electrical heater, $\mathrm{T}$ : thermocouple, $\mathrm{P}$ : crystal/cold cathode pressure gauge, MS: quadrupole mass spectrometer, top quartz window and Xe lamp or LED light sources with controlled on/off intervals. (c) $\mathrm{Pbl}_{2}$ decomposition process driven by visible light $\left(<530 \mathrm{~nm}\right.$ ) above the $\mathrm{Pbl}_{2}$ band gap at $40{ }^{\circ} \mathrm{C}$ to $60{ }^{\circ} \mathrm{C}$. (d) Temperatureassisted $\mathrm{Pbl}_{2}$ evaporation at $\sim 70{ }^{\circ} \mathrm{C}$ in the dark, and (e) $\mathrm{MAPb}_{3}$ photodecomposition and thermal degradation processes leading to irreversible decomposition to organic volatile gas species $\left(\mathrm{CH}_{3} \mathrm{l}+\mathrm{NH}_{3}\right)$, reversible decomposition $\left(\mathrm{CH}_{3} \mathrm{NH}_{2}+\mathrm{HI}\right)$, and reversible generation of $\mathrm{I}_{2}$ and nonvolatile $\mathrm{Pb}^{0}$ under illumination or mild heat conditions. The irreversibility of the process of releasing $\mathrm{CH}_{3} \mathrm{I}+\mathrm{NH}_{3}$ is indicated by a one-directed

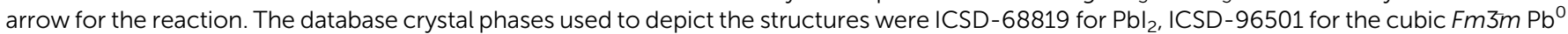
phase and ICSD-238610 for tetragonal $\mathrm{MAPbl}_{3}$. Correlated partial occupation for the methylammonium cation in the $\mathrm{MAPbl}_{3}$ phase was solved using Supercell. ${ }^{12}$ 


\section{Results and discussion}

\section{$\mathrm{PbI}_{2}$ degradation under illumination and dark conditions}

First, we performed photodecomposition experiments on $\mathrm{PbI}_{2}$ (Fig. 1c) in our home-designed experimental setup (Fig. 1b) to verify the adequacy of this setup for $I_{2}$ detection prior to comparison with the photodecomposition of $\mathrm{MAPbI}_{3}$. Two important findings by Dawood et al. ${ }^{10}$ were: (1) $\mathrm{I}_{2}$ gas and metallic $\mathrm{Pb}^{0}$ generation as a consequence of $\mathrm{PbI}_{2}$ photodegradation with an activation energy $\left(E_{\mathrm{a}}\right)$ of $4.7 \mathrm{kcal} \mathrm{mol}^{-1}$, and (2) a threshold wavelength of $520 \mathrm{~nm}$, where only higher photon energies initiate the photodecomposition of $\mathrm{PbI}_{2}$. These findings were also observed in our moisture-free and anaerobic setup; however, $\mathrm{I}_{2}$ gas release was detected at temperatures as low as $40{ }^{\circ} \mathrm{C}$ to $60{ }^{\circ} \mathrm{C}$. We probed four different pulsed light sources: three LED light sources, red $(617 \mathrm{~nm})$, blue $(470 \mathrm{~nm})$, and white $(450+550 \mathrm{~nm})$, and Xe lamp-based simulated solar irradiation (0.55 Sun). Also, an experiment under dark conditions while heating the sample stage to a similar temperature as during the illuminated experiments was carried out to decouple the photodecomposition and thermal degradation (or evaporation) processes (Fig. 1d). Details of the experimental procedures can be found in the Methods section and the ESI. $\uparrow$ Next, the experimental $E_{\mathrm{a}}$ for $\mathrm{I}_{2}$ release during the $\mathrm{PbI}_{2}$ photodecomposition process was extracted in order to determine the feasibility of this photodecomposition reaction. In our analysis, the corresponding $\mathrm{I}_{2}$ releases using different light sources were estimated from the MS data trace pulses; see Table 1.

$E_{\mathrm{a}}$ showed strong dependence on the magnitude and wavelength distribution of the employed light source. The simulated sunlight (Xe lamp, Table 1), which has a broader spectral wavelength, led to the smallest $E_{\mathrm{a}}$ of $\sim 9 \mathrm{kcal} \mathrm{mol}^{-1}$ compared to the narrow wavelength intervals generated by LEDs $\left(E_{\mathrm{a}} \sim 45 \mathrm{kcal}\right.$ and $57 \mathrm{kcal} \mathrm{mol}^{-1}$ for blue and white LEDs, respectively). Interestingly, despite the different photodegradation conditions employed in the current study (i.e., high vacuum and absence of $\mathrm{O}_{2}$ ), the extracted $E_{\mathrm{a}}$ corresponding to $\mathrm{PbI}_{2}$ degradation under Xe lamp illumination $\left(55.2 \mathrm{~mW} \mathrm{~cm}^{-2}\right)$ is in good agreement with the $E_{\mathrm{a}}$ value reported by Dawood et al. $\left(4.7 \mathrm{kcal} \mathrm{mol}^{-1}\right){ }^{10}$

Further investigations using XRD and XPS techniques revealed that $\mathrm{Pb}^{0}$ was the remaining non-volatile product of the photodecomposition of $\mathrm{PbI}_{2}$. More interestingly, this decomposed $\mathrm{Pb}^{0}$ product also showed a reversible recovery process back to $\mathrm{PbI}_{2}$ after brief exposure to $\mathrm{I}_{2}$ gas (ESI Sections $\mathrm{S} 7$ and $\mathrm{S} 8 \dagger$ ).

In summary, the chemical and physical processes extracted from all the sets of degradation and recovery experiments on
$\mathrm{PbI}_{2}$ powders and thin films are summarized by eqn (1) and illustrated in Fig. 1c. Under illumination with photon energies higher than $2.34 \mathrm{eV}(<530 \mathrm{~nm})$, photodecomposition takes place; however, the process is reversible if $\mathrm{Pb}^{0}$ is exposed again to $\mathrm{I}_{2}(\mathrm{~g})$ :

$$
\mathrm{PbI}_{2}(\mathrm{~s}) \stackrel{h v}{\longleftrightarrow} \mathrm{Pb}^{0}(\mathrm{~s})+\mathrm{I}_{2}(\mathrm{~g})
$$

Under dark conditions at moderate temperatures $\left(\sim 70^{\circ} \mathrm{C}\right)$ in high vacuum ( $\sim 10^{-6}$ Torr), $\mathrm{PbI}_{2}$ sublimates in the form of molecules or clusters, as depicted in Fig. 1d and described in eqn (2) below:

$$
\mathrm{PbI}_{2}(\mathrm{~s}) \stackrel{\Delta}{\longrightarrow} n \mathrm{PbI}_{2}(\mathrm{~g})
$$

Notably, no traces of released $\mathrm{I}_{2}$ gas were observed under dark and mild temperature conditions.

\section{Degradation of $\mathrm{MAPbI}_{3}$ and $\mathrm{MAPbBr}_{3}$ under illumination and dark conditions}

In the previous section, the photodecomposition of $\mathrm{PbI}_{2}$ and its volatile $\left(\mathrm{I}_{2}\right)$ and non-volatile $\left(\mathrm{Pb}^{0}\right)$ decomposition products as well as its recovery routes were established based on our homebuilt setup. Identical experimental conditions were applied to $\mathrm{MAPbI}_{3}$ perovskite. In addition, we studied the photodecomposition of $\mathrm{MAPbBr}_{3}$ for comparison purposes, as this material has been reported to show higher stability than $\mathrm{MAPbI}_{3} .^{7, \mathbf{1 3 , 1 4}}$ Currently, the origin of this difference remains largely elusive, and studies of this relative stability have also yielded contradictory results. ${ }^{15}$

$\mathrm{MAPbI}_{3}$ was introduced in the vacuum chamber; after pumping down the system $\left(\sim 10^{-6}\right.$ Torr), a set of experiments with Xe lamp illumination light pulses and heating-only pulses under dark conditions were carried out. Sample temperatures and recorded MS traces are displayed in Fig. 2a and b for each experiment. Firstly, it is interesting to note that the hybrid perovskites required much longer times $(\sim 72 \mathrm{~h})$ to reach a similar level of high vacuum conditions compared to $\mathrm{PbI}_{2}(\sim 6$ h). The MS data helped clarify the reason for this phenomenon. One of the most important findings from this experiment is that in contrast with $\mathrm{PbI}_{2}, \mathrm{MAPbI}_{3}$ powder releases $\mathrm{I}_{2}$ independently of light or dark conditions. The rate of $\mathrm{I}_{2}$ generation was relatively constant during the light/dark pulse conditions (Fig. 2a), whereas $\mathrm{I}_{2}$ was only generated at high temperature pulses $(>\sim 60$ $\left.{ }^{\circ} \mathrm{C}\right)$ applied during heating-in-the-dark conditions (Fig. 2b). Under mild temperature conditions $\left(<\sim 60{ }^{\circ} \mathrm{C}\right), \mathrm{I}_{2}$ release is

Table 1 Estimated ${ }^{a}$ activation energies $\left(E_{\mathrm{a}}, \mathrm{kcal} \mathrm{mol}^{-1}\right)$ corresponding to $\mathrm{I}_{2}$ release reaction (eqn (1))

\begin{tabular}{llll}
\hline Light source & Wavelength $(\mathrm{nm})$ & Temperature $\left({ }^{\circ} \mathrm{C}\right)$ & $\begin{array}{l}\text { Light intensity } \\
\left(\mathrm{mW} \mathrm{cm}^{-2}\right)\end{array}$ \\
\hline White LED & $450+550$ & 50 to 70 & 80 to 110 \\
Blue LED & 470 & 45 to 62 & 71 to 120 \\
Xe lamp & $\sim$ Sun & 35 to 78 & 55
\end{tabular}

${ }^{a}$ Details of the $E_{\mathrm{a}}$ determination and wavelength spectra distribution for each light source are shown in ESI Sections S4 and S5, respectively. 

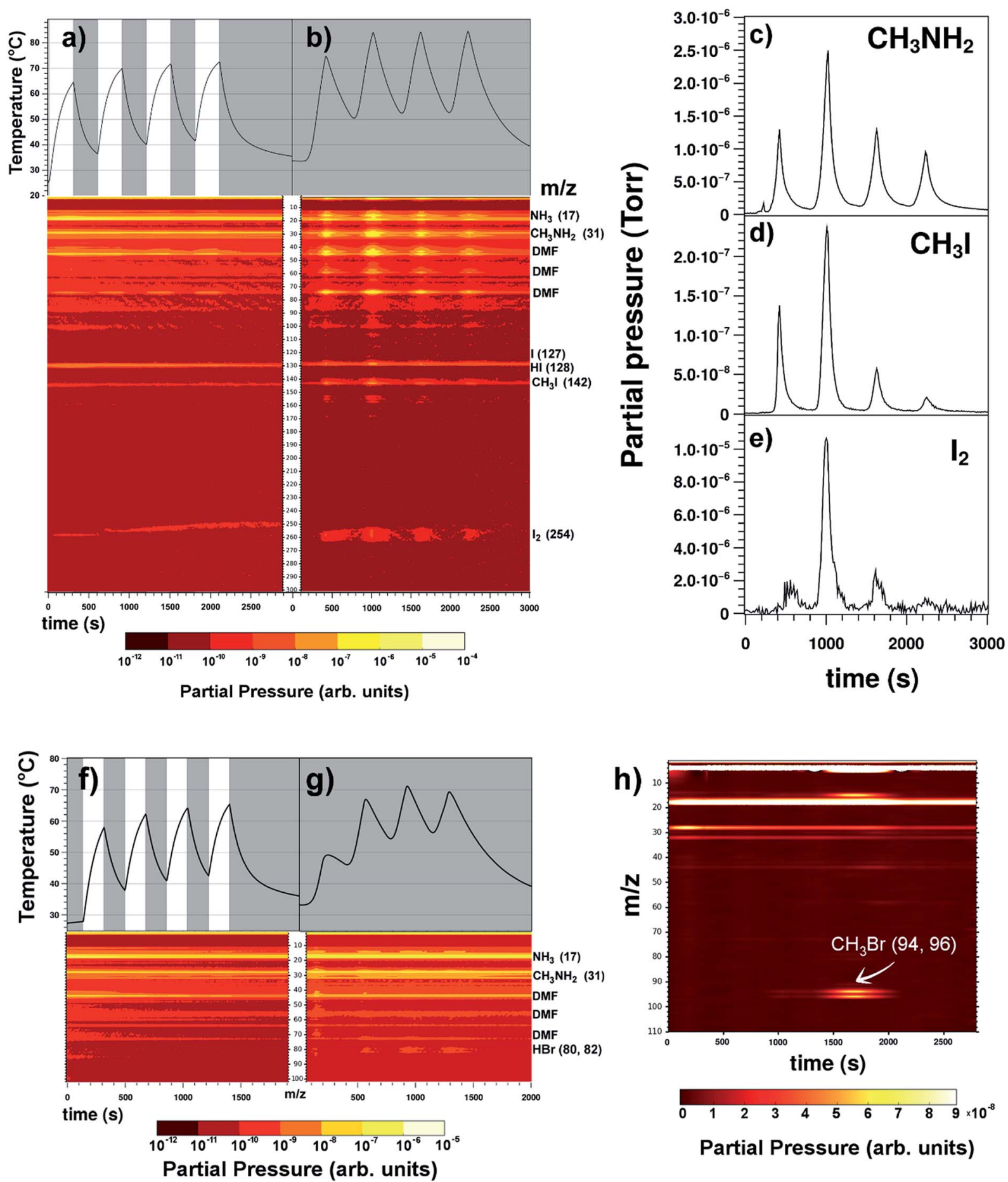

Partial Pressure (arb. units)

Fig. 2 Mass spectrometry profiles of $\mathrm{MAPbl}_{3}$ and $\mathrm{MAPbBr}_{3}$ decomposition products during illumination and heating-in-the-dark pulse experiments. (a) Light/dark intervals ( $5 \mathrm{~min}$ each) on $\mathrm{MAPbl}_{3}$ perovskite using a Xe lamp delivering $55 \mathrm{~mW} \mathrm{~cm}^{-2}$ of light power. White and grey areas represent the light and dark pulse durations, respectively. The black lines correspond to the sample temperature. (b) Heating on/off intervals (5 min each) on the $\mathrm{MAPbl}_{3}$ sample under dark conditions. Species of interest detected in MS are labeled on the right side. The right panel shows calibrated mass traces for (c) $\mathrm{CH}_{3} \mathrm{NH}_{2}$, (d) $\mathrm{CH}_{3}$ land (e) $\mathrm{I}_{2}$ during the heating intervals under dark conditions. ESI Fig. S14 $\uparrow$ shows the calculated $\mathrm{CH}_{3} \mathrm{l} / \mathrm{CH}_{3} \mathrm{NH}_{2}$ molar ratios. (f) Light/dark intervals (3 min each) on the $\mathrm{MAPbBr}_{3}$ perovskite sample. (g) Heating on/off intervals (3 min each) on the $\mathrm{MAPbBr}_{3}$ sample. (h) $\mathrm{m} / z$ traces registered simultaneously during the thermal degradation of $\mathrm{MAPbBr}_{3}$ using a heating rate of $20^{\circ} \mathrm{C} \mathrm{min}^{-1}$ under $\mathrm{He}$ atmosphere in a TG/DTA equipment using the same setting as recently published for $\mathrm{MAPb}_{3} \mathrm{perovskite.}^{9} \mathrm{Release}$ of $\mathrm{CH}_{3} \mathrm{Br}$ $\left(\mathrm{m} / \mathrm{z}=94\right.$ and 96 amu traces) was observed during the thermal degradation. ESI Fig. S13f $\dagger$ shows the fragmentation pattern for $\mathrm{CH}_{3} \mathrm{Br}$ molecule. 
minimized. This indicates that $\mathrm{MAPbI}_{3}$ continues to degrade for some time after it is exposed to the light source. Unlike $\mathrm{PbI}_{2}$, $\mathrm{MAPbI}_{3}$ does not have a wavelength threshold where $\mathrm{I}_{2}$ is released by photodecomposition. If this threshold exists due to the band gap of $\mathrm{MAPbI}_{3}$, an infrared light source should be used; therefore, we preferred to directly heat the sample in dark conditions. Furthermore, in addition to $\mathrm{I}_{2}$ release, $\mathrm{MAPbI}_{3}$ perovskite continuously released organic gas components $\left(\mathrm{CH}_{3} \mathrm{NH}_{2}, \mathrm{HI}, \mathrm{CH}_{3} \mathrm{I}\right.$ and $\left.\mathrm{NH}_{3}\right)$ under vacuum conditions. Upon insertion of $\mathrm{MAPbI}_{3}$ into the vacuum chamber, the background signals associated with $\mathrm{MAPbI}_{3}$ degradation detected by MS were observed to increase. This increase was further enhanced with increase in the number of the light or temperature pulses. Furthermore, mass peaks corresponding to dimethylformamide (DMF) solvent could be observed. ${ }^{16}$ These occluded solvent molecules in the perovskite were expected to be detected because the perovskite powder samples were prepared using a protocol similar to the typical spin coating deposition method; see the Methods section and ESI Section $1 . \dagger E_{\mathrm{a}}$ values for $\mathrm{I}_{2}$ release in $\mathrm{MAPbI}_{3}$ were extracted for comparison with the $\mathrm{PbI}_{2}$ values; see Table 2 .

Interestingly, the $E_{\mathrm{a}}$ value corresponding to $\mathrm{I}_{2}$ release in $\operatorname{MAPbI}_{3}\left(\sim 6 \mathrm{kcal} \mathrm{mol}^{-1}\right)$ was slightly lower than that in $\mathrm{PbI}_{2}$ $\left(\sim 9 \mathrm{kcal} \mathrm{mol}^{-1}\right)$, which indicates that $\mathrm{I}_{2}$ release in $\mathrm{MAPbI}_{3}$ is even slightly more favorable than in $\mathrm{PbI}_{2}$. Because $\mathrm{I}_{2}$ release was observed in dark conditions, $E_{\mathrm{a}}$ was also calculated for $\mathrm{MAPbI}_{3}$ from the signals of $I_{2}$ release during the heating-in-the-dark experiments. We noted that the $E_{\mathrm{a}}$ in the heating-in-the-dark conditions was around three times higher than that under light exposure, indicating that a light-driven process is dominant during $\mathrm{MAPbI}_{3}$ degradation.

The similarities and differences found for $\mathrm{MAPbI}_{3}$ and $\mathrm{PbI}_{2}$ during these light/heat stress experiments have two possible causes (considering that the $\mathrm{MAPbI}_{3}$ material system is to some extent represented by $\mathrm{PbI}_{2}$ with intercalated $\mathrm{MA}^{+}$cations): (i) in contrast to $\mathrm{PbI}_{2}, \mathrm{MAPbI}_{3}$ shows a smaller band gap, suggesting that additional photons with lower energies are effective for exciton and/or free charge generation at the same illumination power, and (ii) $\mathrm{I}_{2}$ release in $\mathrm{MAPbI}_{3}$ does not require a twoexciton mechanism as in $\mathrm{PbI}_{2}$ because $\left[\mathrm{PbI}_{6}\right]$ octahedral distortion produces shorter I-I bond distances that are consistent with the formation of neutral $\mathrm{I}_{2}$ defects, ${ }^{17}$ which potentially facilitates the release of $\mathrm{I}_{2} \cdot{ }^{18}$

For the sake of completeness, the same photodecomposition and thermal decomposition experiments performed on $\mathrm{PbI}_{2}$

Table 2 Estimated ${ }^{a}$ activation energies $\left(\mathrm{kcal} \mathrm{mol}^{-1}\right)$ of the degradation reactions releasing $\mathrm{I}_{2}$ in $\mathrm{MAPbl}_{3}$ samples as measured by $\mathrm{MS}$ spectrometry

\begin{tabular}{llll}
\hline $\begin{array}{l}\text { Light/dark } \\
\text { conditions }\end{array}$ & $\begin{array}{l}\text { Temperature } \\
\left({ }^{\circ} \mathrm{C}\right)\end{array}$ & $\begin{array}{l}\text { Light intensity } \\
\left.(\mathrm{mW} \mathrm{cm})^{-2}\right)\end{array}$ & $\begin{array}{l}E_{\mathrm{a}} \\
\left(\mathrm{kcal} \mathrm{mol}^{-1}\right)\end{array}$ \\
\hline Xe lamp & 35 to 72 & 55 & 6 \\
Heat in dark & 60 to 84 & 0 & 18
\end{tabular}

${ }^{a}$ Details of the $E_{\mathrm{a}}$ determination and wavelength spectra for each light source are shown in ESI Sections S4 and S5, respectively. and $\mathrm{MAPbI}_{3}$ were applied to $\mathrm{MAPbBr}_{3}$ to elucidate its decomposition products (e.g., is $\mathrm{Br}_{2}$ generated? What organic molecules are released from degraded $\mathrm{MAPbBr}_{3}$ ?) and associate it with the reported disparity in the stability of $\mathrm{MAPbBr}_{3}$ compared to $\mathrm{MAPbI}_{3}$. Comparing the experimental observations of the photodecomposition of $\mathrm{MAPbI}_{3}$ and $\mathrm{MAPbBr}_{3}$ perovskites, the main difference was that under vacuum and near room temperature conditions, $\mathrm{MAPbI}_{3}$ showed numerous degradation gas products (i.e., $\mathrm{CH}_{3} \mathrm{I}$ and $\mathrm{NH}_{3} ; \mathrm{CH}_{3} \mathrm{NH}_{2}$ and $\mathrm{HI}$; and $\mathrm{I}_{2}$ ); however, $\mathrm{MAPbBr}_{3}$ only released $\mathrm{CH}_{3} \mathrm{NH}_{2}$ and $\mathrm{HBr}$ (and solvent); see Fig. $2 \mathrm{f}$ and $\mathrm{g}$. We emphasize that the $\mathrm{CH}_{3} \mathrm{Br}, \mathrm{NH}_{3}$, and $\mathrm{Br}_{2}$ gaseous species were detected below the signalsensitivity threshold of MS under vacuum conditions in a low temperature range $\left(30^{\circ} \mathrm{C}\right.$ to $\left.70{ }^{\circ} \mathrm{C}\right)$. On the other hand, under almost atmospherically inert $\mathrm{He}$ pressure conditions and at high temperatures $\left(\sim 300{ }^{\circ} \mathrm{C}\right), \mathrm{MAPbI}_{3}$ and $\mathrm{MAPbBr}_{3}$ underwent similar degradation processes of releasing $\mathrm{CH}_{3} \mathrm{I} / \mathrm{NH}_{3}$ gas products: $\left(\mathrm{MAPbI}_{3}\right)^{9}$ and $\mathrm{CH}_{3} \mathrm{Br} / \mathrm{NH}_{3}\left(\mathrm{MAPbBr}_{3}\right)$ (Fig. 2h), respectively. Table 3 summarizes both the experimental conditions and detected products from the degradation tests carried out on perovskites.

In summary, the chemical processes extracted from all the sets of degradation and recovery experiments on halide perovskite powders and thin films of $\mathrm{MAPbI}_{3}$ are summarized by eqn (3) and (4) and illustrated in Fig. 1e. Under illumination or dark, low-heating conditions compatible with photovoltaic operation, the photodecomposition and thermal decomposition reactions occurring are:

$$
\begin{aligned}
& \operatorname{MAPbI}_{3}(\mathrm{~s}) \stackrel{h v \text { or } \Delta}{\longrightarrow} \\
& \mathrm{PbI}_{2}(\mathrm{~s})+\mathrm{Pb}^{0}(\mathrm{~s})+\mathrm{I}_{2}(\mathrm{~g})+\mathrm{CH}_{3} \mathrm{NH}_{2}(\mathrm{~g})+\mathrm{CH}_{3} \mathrm{I}(\mathrm{g})+\mathrm{HI}(\mathrm{g})+\mathrm{NH}_{3}(\mathrm{~g})
\end{aligned}
$$

$$
\mathrm{MAPbBr}_{3}(\mathrm{~s}) \stackrel{h v \text { or } \Delta}{\longrightarrow} \mathrm{PbBr}_{2}(\mathrm{~s})+\mathrm{CH}_{3} \mathrm{NH}_{2}(\mathrm{~g})+\mathrm{HBr}(\mathrm{g})
$$

$\mathrm{CH}_{3} \mathrm{X} / \mathrm{NH}_{3}$ (X = I or $\mathrm{Br}$ ) molecules are reported to be the thermodynamically driven products of degradation of methylammonium cations $;^{19}$ this degradation is irreversible to reform $\mathrm{MA}^{+} .{ }^{9}$ In contrast, the release of $\mathrm{CH}_{3} \mathrm{NH}_{2}+\mathrm{HX}$ is considered to be reversible because of its high reactivity in neutralizing back

Table 3 Summary of experimentally detected volatile degradation products under different environmental conditions. For comparison,

\begin{tabular}{|c|c|c|}
\hline Perovskite type & $\begin{array}{l}\text { Inert atmosphere: } \\
\text { vacuum, } T \sim \text { room }\end{array}$ & $\begin{array}{l}\text { Inert atmosphere: } \sim 1 \mathrm{~atm} \text {, } \\
\text { helium } T \sim 300{ }^{\circ} \mathrm{C}\end{array}$ \\
\hline $\mathrm{MAPbI}_{3}$ & $\begin{array}{l}\text { (1) } \mathrm{CH}_{3} \mathrm{NH}_{2}+\mathrm{HI}^{a, c} \\
\text { (2) } \mathrm{NH}_{3}+\mathrm{CH}_{3} \mathrm{I}^{a, c, d} \\
\text { (3) } \mathrm{I}_{2}{ }^{a}\end{array}$ & $\mathrm{NH}_{3}+\mathrm{CH}_{3} \mathrm{I}^{b}$ \\
\hline $\mathrm{MAPbBr}_{3}$ & $\mathrm{CH}_{3} \mathrm{NH}_{2}+\mathrm{HBr}^{a}$ & $\mathrm{NH}_{3}+\mathrm{CH}_{3} \mathrm{Br}^{a}$ \\
\hline
\end{tabular}
previously reported degradation products are also indicated in the table 
to $\mathrm{MA}^{+}$and $\mathrm{X}^{-}$. In fact, $\mathrm{CH}_{3} \mathrm{NH}_{2} / \mathrm{HI}$ gases have been demonstrated as excellent reagents that can be used to directly synthesize $\mathrm{MAPbI}_{3}$ perovskite. ${ }^{\mathbf{2 1 , 2 2}}$ Therefore, under encapsulated conditions, it is not correct to consider $\mathrm{CH}_{3} \mathrm{NH}_{2}+\mathrm{HI}$ released gases as degradation products of perovskites because they can resynthesize $\mathrm{MAPbI}_{3}$. A unique situation where $\mathrm{CH}_{3} \mathrm{NH}_{2}+\mathrm{HX}$ can be considered as degradation products is when perovskites are placed in an open system (e.g. nonencapsulated solar cells) where back reaction is obviously inhibited because the released gases are permanently leaked. As highlighted in our work, we determined $\mathrm{CH}_{3} \mathrm{NH}_{2}+\mathrm{HI}$ release to be a benign or reversible pathway of degradation because it does not lead to permanent degradation, but to a chemical equilibrium of formation and destruction of perovskite (Fig. 1e).

On the other hand, the back formation to MAX or MAPbX from the released $\mathrm{CH}_{3} \mathrm{X}+\mathrm{NH}_{3}$ molecules is thermodynamically unfavorable and prone to form non-primary ammonium salts, as previously reported. ${ }^{9}$ Therefore, we assign the $\mathrm{CH}_{3} \mathrm{X}+\mathrm{NH}_{3}$ release as an authentic detrimental pathway for perovskite degradation. If such a degradation path is taking place even in smaller proportions, as represented in Fig. $2 \mathrm{~d}$ and elsewhere, ${ }^{\mathbf{1 9}}$ it would result in short time stability of methylammoniumbased hybrid perovskite solar cells even if careful encapsulation is employed. In view of the above points, it can be understood that $\mathrm{MAPbBr}_{3}$ is more stable than $\mathrm{MAPbI}_{3}$ because this detrimental path releasing $\mathrm{CH}_{3} \mathrm{Br}+\mathrm{NH}_{3}$ was not observed at low temperatures, i.e., $40{ }^{\circ} \mathrm{C}$ to $80{ }^{\circ} \mathrm{C}$ (see Table 3 and eqn (4)). Consequently, an encapsulated sample of methylammoniumbased bromide perovskite would be more stable than I-based perovskite under near ambient conditions.

\section{Photostability and thermal stability of pristine perovskite: implications for its operational stability in solar cell devices}

Perovskite thin films employed in photovoltaic devices under working conditions can follow a different degradation path compared to that of the pristine polycrystalline powder samples used in this study. In fact, in this study on photodecomposition and thermal decomposition of perovskites, the light harvester material was intentionally placed under optimistic and favorable conditions for perovskite stability, avoiding contact with any other compound (e.g., HTL, ETL, dopants used in HTL, moisture or oxygen) and without any applied bias. At this point, it is important to recall that the chemical synthesis procedure of pristine perovskite as well as the temperature and illumination conditions during the tests can be considered to resemble the working conditions to which perovskite is deposited in devices.

With regard to selective contacts, the side reactions that will be suffered by a specific HTL used in photovoltaic devices upon exposure to the gas by-products ( $\mathrm{HI}, \mathrm{CH}_{3} \mathrm{I}, \mathrm{I}_{2}, \mathrm{CH}_{3} \mathrm{NH}_{2}$ and $\mathrm{NH}_{3}$ ) released by $\mathrm{MAPbI}_{3}$, for example, during working conditions (eqn (3)) are out of the scope of this work. However, it is suggested that, rarely, the spiro functional group in the spiroMeOTAD molecule, which is widely used as an HTL, can resist the attack of the above chemical gas agents over a photovoltaic device lifetime of $\sim 20$ years. Therefore, avoiding contact with other compounds related only to the device helps reveal the intrinsic pathways of photodecomposition and thermal decomposition in perovskite. It can be reasonably considered that selective contacts cannot avoid these intrinsic decomposition paths in perovskites, which are driven by light and temperature. In contrast, decomposition can increase due to unknown side reactions that are specific for each selective layer case.

On the other hand, the voltage applied to thin films is a relevant parameter to consider when measuring photodegradation and thermal degradation in halide perovskites. With regard to degradation paths for perovskite under applied bias, additional experimental work was carried out in a specially designed $\mathrm{MAPbI}_{3}$ thin-film device consisting of two-gold electrode contacts (spaced by 70 microns) deposited on $\mathrm{MAPbI}_{3}$. Controlled bias voltage was applied on the gold electrodes, generating an electric field corresponding to that typically

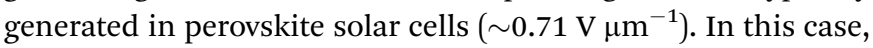
the perovskite layer was protected from moisture and oxygen by a top CYTOP layer. The core levels of $\mathrm{MAPbI}_{3}$ thin films were investigated using XPS mapping on lateral devices (Fig. 3). As can be seen in Fig. 3a, a uniform distribution of $\mathrm{Pb}^{2+}$ and $\mathrm{I}^{-}$was found for $\mathrm{MAPbI}_{3}$. However, after applying the electric field (Fig. 3b), a clear decrease as well as a non-uniform distribution of $\mathrm{Pb}^{2+}$ and $\mathrm{I}^{-}$was observed. XPS spectra (Fig. 3c) were also collected from the area between the electrodes (using a $27 \mu \mathrm{m}$ detector slit). Depletion of $\mathrm{Pb}^{0}$ and $\mathrm{Pb}^{2+}$ was clearly observed on the negative electrode side, where a reduction process takes place in the perovskite under the externally applied electric field. Similarly, a broadening of the FWHM belonging to I $3 \mathrm{~d}$ core level (from 1.0 to $1.4 \mathrm{eV}$ ) was observed after applying the electric field. The broadening of the I 3d FWHM indicates the formation of new iodine species, such as $\mathrm{CH}_{3} \mathrm{I}, \mathrm{HI}$ and $\mathrm{I}_{2}$. Overall, the XPS results in this experiment are consistent with the observations described in the case of unbiased pristine perovskites. However, the most impressive observation in these biased thin-film perovskite experiments is the violent in situ release of gases observed in the form of "bubbles" formed under the CYTOP transparent layer. The CYTOP layer effectively impedes the release of these volatile gases from perovskite to the ambient environment (Fig. 3d and the video film deposited in the ESI $\dagger$ file).

The challenges associated with these chemical instability issues found in $\mathrm{MAPbI}_{3}$ perovskite must be mitigated in perovskite solar cells. Below, four guidelines/recommendations based on the outputs of the above degradation study may aid the design of better devices with increased operational stability:

(1) Careful selection of cations for the A site in the perovskite structure, replacing $\mathrm{MA}^{+}$with a suitable mixture of $\mathrm{Cs}^{+} / \mathrm{FA}^{+}$ (cesium and formamidinium) cations. The irreversible reaction $\left(\mathrm{CH}_{3} \mathrm{I} / \mathrm{NH}_{3}\right.$ formation and release route) suffered by $\mathrm{MA}^{+}$can be addressed in principle by replacing it with a mixture of $\mathrm{Cs}^{+} / \mathrm{FA}^{+}$ (cesium and formamidinium cations) in the A site of perovskite without large efficiency losses. Currently, it may be difficult if not impossible to find an atomic or molecular replacement for iodide ion while maintaining excellent light harvesting properties. 
(a) Before bias $\mathrm{V}$

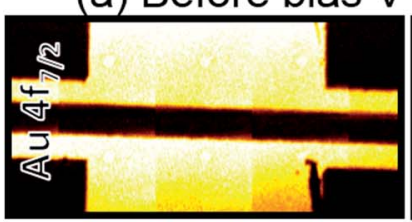

(b) After bias $\mathrm{V}$
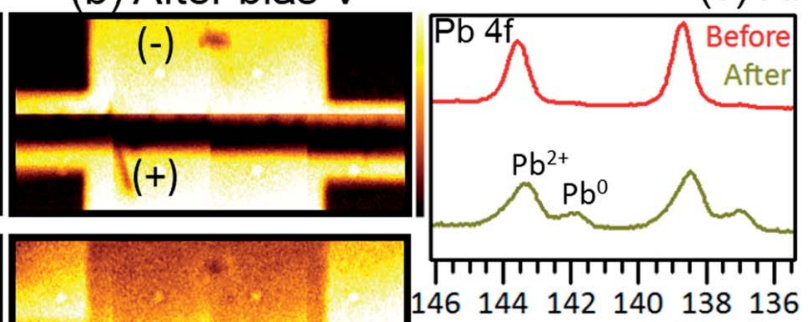

(c) XPS spectra
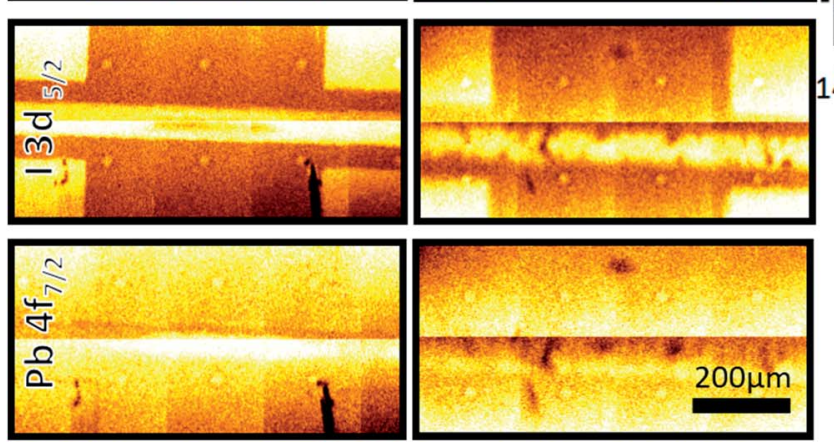

(d) Video frame of illuminated device under $\mathrm{V}$ bias

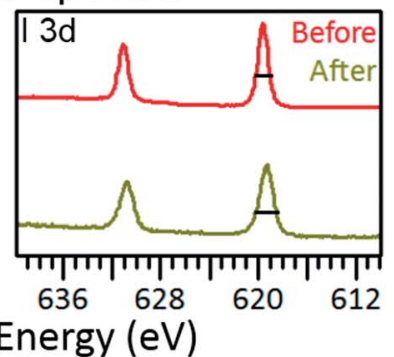

Fig. 3 XPS mapping and spectra (Al- $K_{\alpha}=1486.6 \mathrm{eV}$ ) of $\mathrm{MAPb}_{3}$ thin films before and after applying a voltage bias. $(\mathrm{a}, \mathrm{b}) \mathrm{XPS}$ maps of $\mathrm{Au} 4 \mathrm{f}_{7 / 2}, \mathrm{I} 3 \mathrm{~d}_{5 / 2}$, and $\mathrm{Pb} 4 \mathrm{f}_{7 / 2}$ core levels and (c) XPS spectra of $\mathrm{Pb} 4 \mathrm{f}$ and I $3 \mathrm{~d}$ core levels before and after application of an electrical bias. The FWHM values of the I $3 \mathrm{~d}$ peak are $1 \mathrm{eV}$ and $1.4 \mathrm{eV}$ before and after application of bias, respectively. The bias voltage applied was $50 \mathrm{~V}$ across $70 \mu \mathrm{m}, \varepsilon=50 / 70=$ $0.71 \mathrm{~V} \mathrm{\mu m}^{-1}$. Under conventional cell operation at the maximum power point, the bias voltage would be $0.8 \mathrm{~V}$ across $0.5 \mu \mathrm{m}$ of perovskite, $\varepsilon=$ $0.8 / 0.5=1.6 \mathrm{~V} \mathrm{\mu m} \mathrm{m}^{-1}$. The $\mathrm{Pb}^{0} / \mathrm{Pb}^{2+}$ composition ratio is 0.20 in the biased degradation sample. This is similar to the 0.18 composition ratio obtained from an unbiased sample (see Table S2 and Fig. S15b †). The composition ratio for I $3 \mathrm{~d}$ in the biased degraded sample is 1.8 . This ratio is 1.6 for the unbiased degraded sample (see Table S2 and Fig. S17a†). (d) Video frame of the illuminated device under V bias showing the release of volatile gases in the negative electrode and trapped gas bubbles under the transparent CYTOP layer. See the ESI $\uparrow$ file for a full video of the experiment.

(2) Encapsulation of devices is necessary not only to avoid contact with external agents, but also to prevent leakage of volatile decomposition products $\left(\mathrm{I}_{2}\right.$ for all iodine-based perovskites and $\mathrm{CH}_{3} \mathrm{I} / \mathrm{NH}_{3} / \mathrm{CH}_{3} \mathrm{NH}_{2} / \mathrm{HI}$ for the specific case of $\mathrm{MA}^{+}$based perovskites). Encapsulation ensures that the perovskite is inside a thermodynamically closed system, allowing only energy exchange and chemical equilibrium concentrations of solid and gas products according to the law of mass action at the perceived temperature.

(3) Selective contacts in solar cells, especially organic molecules or polymer-based HTM, must be as chemically inert as possible to be unaffected by an environment rich in highly acidic molecules ( $\mathrm{HI})$, good methylation reagents $\left(\mathrm{CH}_{3} \mathrm{I}\right)$, oxidizing agents $\left(\mathrm{I}_{2}\right)$, and weak bases $\left(\mathrm{CH}_{3} \mathrm{NH}_{2}, \mathrm{NH}_{3}\right)$.

(4) In relation to point no. 2 above, a hybrid halide perovskite material is assumed to undergo cycles of dynamic formation and decomposition processes; this can gradually decrease its crystalline grain size over time. Therefore, efforts to deposit large crystalline perovskite domains may not be beneficial to the long term stability of devices.

\section{Conclusions}

In summary, hybrid lead iodide perovskite has been demonstrated as a semiconductor material that exhibits dynamic processes of continuous decomposition and formation under visible light and/or mild temperature stimulus compatible with solar cell operation conditions. $\mathrm{I}_{2}$ gas is released from $\mathrm{MAPbI}_{3}$ even in dark conditions during mild heating at temperatures as low as $40{ }^{\circ} \mathrm{C}$ to $80{ }^{\circ} \mathrm{C}$, which correspond to solar cell working temperatures. Fortunately, this photodecomposition reaction is reversible at least for $\mathrm{PbI}_{2}$, because back formation of $\mathrm{Pb}^{0}+\mathrm{X}_{2}$ $\rightleftharpoons \mathrm{PbX}_{2}$ is observed. Because $\mathrm{MAPbI}_{3}$ also decomposes to $\mathrm{CH}_{3} \mathrm{I}$ $+\mathrm{NH}_{3}$, which corresponds to the irreversible degradation pathway, strategies such as replacement of $\mathrm{MA}^{+}$cations by more stable Cs/FA combinations are suggested. $\mathrm{MAPbBr}_{3}$ shows enhanced stability compared to $\mathrm{MAPbI}_{3}$ because the former decomposes only into $\mathrm{CH}_{3} \mathrm{NH}_{2}+\mathrm{HBr}$ at ambient temperature, which allows a clean self-healing process. Therefore, to further improve the operational stability of hybrid perovskite solar cells, detailed understanding of how to control of all these photodegradation and thermal degradation processes is required. Four guidelines/ recommendations based on the outputs of the above degradation study may aid the design of better devices with increased operational stability. First, encapsulation of the device is necessary not only to avoid contact with ambient air, but also to prevent leakage of volatile released products. Second, careful selection of the organic cations in the A site of the compositional perovskite formula is necessary to avoid irreversible reactions. Third, selective contacts must be as chemically inert as possible toward volatile released products which can provoke undesired side-reactions. Finally, a hybrid halide perovskite material is assumed to undergo a dynamic formation and decomposition process; this can gradually decrease its crystalline grain size with time. Therefore, efforts to deposit large, highly crystalline perovskite may not be beneficial to the long term stability of devices. 


\section{Methods}

\section{Materials}

Lead(II) iodide $\left(\mathrm{PbI}_{2}, 99.9 \%\right)$ was purchased from Tokyo Chemical Industry Co., Ltd, lead(II) bromide $\left(\mathrm{PbBr}_{2}, 99.999 \%\right)$ was purchased from Sigma-Aldrich, and methylammonium iodide (MAI) and methylammonium bromide (MABr) were purchased from Dyesol Limited. All chemicals were used as received without any further purification. Hybrid perovskites in powdered polycrystalline material form were obtained by mimicking the procedure to deposit perovskite thin films on substrates. Briefly, $1 \mathrm{~mL}$ of DMF (Wako Pure Chemical Industries) solution $(\sim 1 \mathrm{M})$ containing the desired stoichiometric precursor quantities to synthesize $\mathrm{MAPbI}_{3}$ or $\mathrm{MAPbBr}_{3}$ was poured on a mortar $10 \mathrm{~cm}$ in diameter and maintained at $100{ }^{\circ} \mathrm{C}$ inside a fume hood. The precursor solution was slowly spread on the mortar surface with the aid of the pestle. The DMF solvent was evaporated within 1 to 2 minutes, leaving a solid crystalline material on the mortar. The crystal was then carefully collected. The perovskite phase purity (i.e. absence of $\mathrm{PbI}_{2}$ ) and crystalline parameters were verified by powder XRD measurements (ESI Fig. S1 $\dagger$ ). Powder XRD data were recorded in glazing incidence XRD (GIXRD) mode (detector scan, omega $=0.5^{\circ}$ ) using a D8 Bruker Discover (Cu-K $\alpha 1$ radiation) with $2 \theta$ degrees varying from $10^{\circ}$ to $55^{\circ}$ using $0.5 \mathrm{~s}$ acquisition times for every $0.02^{\circ} 2 \theta$ interval. Quantitative analysis of the powder samples was performed by fitting the entire XRD pattern with the MAUD 2.71 software package. ${ }^{23}$

\section{Photodecomposition experiments}

(i) Probing of volatile gases. Fresh samples of $\mathrm{PbI}_{2}(\sim 180$ $\mathrm{mg}$ ) were loaded in the sample holder located inside the chamber (ESI Fig. S2a $\dagger$ ). Upon reaching a high vacuum level $\left(\sim 10^{-8}\right.$ to $10^{-6}$ Torr) monitored by a pressure gauge, the MS spectrometer was switched on. The temperature of the sample under dark conditions and high vacuum conditions were slightly high $\left(30{ }^{\circ} \mathrm{C}\right.$ to $\left.35{ }^{\circ} \mathrm{C}\right)$ due to the electron-ionization (radiative heating) of MS. Light power pulses of white, red, and blue LEDs were programmed using an Autolab PGSTAT204 potentiostat including the LED driver box accessory (Metrohm AG). Simulated sunlight was generated using a $150 \mathrm{~W}$ short-arc Xe lamp from a Portable Solar Simulator (PEC-L01, Peccell Technologies Inc). Light pulses in the solar simulator were controlled remotely by a homemade computer program and actuator. The light powers delivered by both the solar simulator and LEDs were calibrated using a calibrated silicon photodiode accounting for the quartz window and the distance from the light source to the sample holder (ESI Section S5† for light power calibration details). Volatile degradation traces were recorded using a quadrupole MS equipped with an electron multiplier detector (SRS Stanford Research Systems, RGA300). The conventional Faraday cup detector in the MS was not reliable for detecting diiodine traces at nearly room temperature. The raw MS signals were calibrated using sensitivity factors calculated according to the procedure described in ESI Section S6. $\dagger$ (ii) Probing of non-volatile products. The chemical compositions of the non-volatile products (i.e. remaining solid material) of the photodecomposition experiments were determined by XRD and XPS (ESI Section S7 $\dagger$ ). The surface chemical properties of $\mathrm{PbI}_{2}, \mathrm{MAPbI}_{3}$ and $\mathrm{MAPbBr}_{3}$ were characterized by XPS (Kratos AXIS ULTRA HAS, monochromated Al-K $\alpha=1486.6$ eV) in order to observe the effects of light exposure in vacuum. The binding energy (BE) was calibrated by measuring the Fermi edge $\left(E_{\mathrm{F}}=0 \mathrm{eV}\right)$ and $\mathrm{Au}-4 \mathrm{f}_{7 / 2}(84.0 \mathrm{eV})$ on a clean Au surface. Freshly prepared samples were first analyzed by XPS. The BE scale of $\mathrm{PbI}_{2}$ spectra was calibrated using the adventitious carbon peak (C 1s) at $\sim 285 \mathrm{eV}$ as a reference. ${ }^{\mathbf{2 4 , 2 5}}$ In our samples, residual amounts of adventitious carbon were unavoidable due to air exposure prior to the XPS measurements. In addition, a C 1s signal originating from residual solvents can be also expected. Great care was taken in order to minimize X-ray exposure time when acquiring XPS signals on the $\mathrm{PbI}_{2}, \mathrm{MAPbI}_{3}$, and $\mathrm{MAPbBr}_{3}$ samples. X-ray-induced sample damage was monitored by taking five consecutive scans and comparing the spectra. The acquisition time for each scan varied from 20 to $70 \mathrm{~s}$ depending on the core level region. The five scans were averaged to a single spectrum if no significant change was observed. Peak fittings and standard deviation calculations were performed with CasaXPS 2.3.16. The Shirley function was used to simulate the background signal due to inelastic scattering processes. ${ }^{26}$ Raw XPS spectra of $\mathrm{Pb} 4 \mathrm{f}, \mathrm{I} 3 \mathrm{~d}$ (for $\mathrm{PbI}_{2}$ and $\mathrm{MAPbI}_{3}$ ), Br 3d (for $\mathrm{MAPbBr}_{3}$ ), C 1s, and N 1s (for $\mathrm{MAPbI}_{3}$ and $\mathrm{MAPbBr}_{3}$ ) were fitted with Gaussian-Lorentzian (G-L) functions to quantitatively determine their BE peak positions, full width at half maximum (FWHM), and relative spectral areas. The intensity ratios between the $4 \mathrm{f}_{7 / 2}$ and $4 \mathrm{f}_{5 / 2}(\mathrm{~Pb})$ and $3 \mathrm{~d}_{5 / 2}$ and $3 \mathrm{~d}_{3 / 2}$ (I and $\mathrm{Br}$ ) doublets due to spin-orbit coupling were 1.33 and 1.50 ( $\pm 3 \%$ error), respectively. The concentrations of the different elements (metallic- $\mathrm{Pb}, \mathrm{I}, \mathrm{Br}, \mathrm{C}$ and $\mathrm{N}$ ) relative to $\mathrm{Pb}^{2+}$ were estimated from the fitted areas after normalization with the atomic sensitivity factors (ASF). ${ }^{27-29}$

An extension of the Experimental section with full details is deposited in the ESI, $\dagger$ including further details on the calibration of light sources used in this work and the MS calibration.

\section{Comment from authors}

During the course of the review of this manuscript, an article (DOI: 10.1038/s41563-018-0038-0) appeared describing the enhancement of ion conduction in perovskite by the effect of light. This is a surprising effect that is assumed to be due to the generation of vacancies on perovskite; this effect can be better understood based on our MS measurements during the degradation tests under mild temperature and light conditions.

\section{Author contributions}

Y. B. Q. conceived the idea and supervised the work. E. J. J. P. and Y. B. Q. designed the experiments. E. J. J. P. carried out all measurements (except XPS), data analysis, and results interpretation and wrote the first version of the manuscript. L. K. O., M. M. and Z. H. performed XPS measurements and assisted 
with XPS data analysis and interpretation. E. J. J. P. recorded and edited the "bubbling" perovskite video deposited in the ESI $\dagger$ file. All authors assisted with interpretation of the results and contributed to writing the manuscript.

\section{Conflicts of interest}

There are no conflicts to declare.

\section{Acknowledgements}

This work was supported by funding from the Energy Materials and Surface Sciences Unit of the Okinawa Institute of Science and Technology Graduate University, the OIST Proof of Concept (POC) Program, the OIST R\&D Cluster Research Program, and JSPS KAKENHI Grant Number 15K17925 and JP18K05266. We thank Steven D. Aird, the Technical Editor at Okinawa Institute of Science and Technology Graduate University, for valuable suggestions in revising the manuscript.

\section{References}

1 A. Kojima, K. Teshima, Y. Shirai and T. Miyasaka, J. Am. Chem. Soc., 2009, 131, 6050-6051.

2 Y. Yang and J. You, Nature, 2017, 544, 155-156.

3 G. Grancini, C. Roldan-Carmona, I. Zimmermann, E. Mosconi, X. Lee, D. Martineau, S. Narbey, F. Oswald, F. De Angelis, M. Graetzel and others, Nature, 2017, 8, 1.

4 S. G. Hashmi, A. Tiihonen, D. Martineau, M. Ozkan, P. Vivo, K. Kaunisto, V. Ulla, S. M. Zakeeruddin and M. Grätzel, J. Mater. Chem. A, 2017, 5, 4797-4802.

5 T. Matsui, J.-Y. Seo, M. Saliba, S. M. Zakeeruddin and M. Grätzel, Adv. Mater., 2017, 1606258.

6 W. Nie, J.-C. Blancon, A. J. Neukirch, K. Appavoo, H. Tsai, M. Chhowalla, M. A. Alam, M. Y. Sfeir, C. Katan, J. Even, S. Tretiak, J. J. Crochet, G. Gupta and A. D. Mohite, Nat. Commun., 2016, 7, 11574.

7 S. Wang, Y. Jiang, E. J. Juarez-Perez, L. K. Ono and Y. B. Qi, Nat. Energy, 2016, 2, 16195.

8 R. G. Wilks and M. Bär, Nat. Energy, 2017, 2, 16204.

9 E. J. Juarez-Perez, Z. Hawash, S. R. Raga, L. K. Ono and Y. B. Qi, Energy Environ. Sci., 2016, 9, 3406-3410.

10 R. I. Dawood, A. J. Forty and M. R. Tubbs, Proc. R. Soc. London, Ser. A, 1965, 284, 272-288.

11 J. Schoonman, Chem. Phys. Lett., 2015, 619, 193-195.
12 K. Okhotnikov, T. Charpentier and S. Cadars, J. Cheminf., 2016, 8, 17.

13 R. K. Misra, S. Aharon, B. Li, D. Mogilyansky, I. Visoly-Fisher, L. Etgar and E. A. Katz, J. Phys. Chem. Lett., 2015, 6, 326-330.

14 R. K. Misra, L. Ciammaruchi, S. Aharon, D. Mogilyansky, L. Etgar, I. Visoly-Fisher and E. A. Katz, ChemSusChem, 2016, 9, 2572-2577.

15 A. F. Akbulatov, S. Y. Luchkin, L. A. Frolova, N. N. Dremova, K. L. Gerasimov, I. S. Zhidkov, D. V. Anokhin, E. Z. Kurmaev, K. J. Stevenson and P. A. Troshin, J. Phys. Chem. Lett., 2017, 1211-1218.

16 A. E. Williams, P. J. Holliman, M. J. Carnie, M. L. Davies, D. A. Worsley and T. M. Watson, J. Mater. Chem. A, 2014, 2, 19338-19346.

17 J. L. Minns, P. Zajdel, D. Chernyshov, W. van Beek and M. A. Green, Nat. Commun., 2017, 8, 15152.

18 J. Xie, Y. Liu, J. Liu, L. Lei, Q. Gao, J. Li and S. Yang, J. Power Sources, 2015, 285, 349-353.

19 A. Latini, G. Gigli and A. Ciccioli, Sustainable Energy Fuels, 2017, 1, 1351-1357.

20 J. Chun-Ren Ke, A. S. Walton, D. J. Lewis, A. Tedstone, P. O'Brien, A. G. Thomas and W. R. Flavell, Chem. Commun., 2017, 53, 5231-5234.

21 S. R. Raga, L. K. Ono and Y. B. Qi, J. Mater. Chem. A, 2016, 4, 2494-2500.

22 S. Pang, Y. Zhou, Z. Wang, M. Yang, A. R. Krause, Z. Zhou, K. Zhu, N. P. Padture and G. Cui, J. Am. Chem. Soc., 2016, 138, 750-753.

23 L. Lutterotti, R. Vasin and H.-R. Wenk, Powder Diffr., 2014, 29, 76-84.

24 B. Conings, J. Drijkoningen, N. Gauquelin, A. Babayigit, J. D'Haen, L. D'Olieslaeger, A. Ethirajan, J. Verbeeck, J. Manca, E. Mosconi, et al., Adv. Energy Mater., 2015, 5, 1500477.

25 B. Philippe, B.-W. Park, R. Lindblad, J. Oscarsson, S. Ahmadi, E. M. J. Johansson and H. Rensmo, Chem. Mater., 2015, 27, 1720-1731.

26 D. A. Shirley, Phys. Rev. B: Solid State, 1972, 5, 4709.

27 J. Scofield, J. Electron Spectrosc. Relat. Phenom., 1976, 8, 129137.

28 S. Olthof and K. Meerholz, Sci. Rep., 2017, 7, 40267.

29 S. Nakayashiki, H. Daisuke, Y. Ogomi and S. Hayase, J. Photonics Energy, 2015, 5, 057410. 